\section{The effect of fabrication techniques of temporary crowns on the gingiva health}

\author{
Eri H. Jubhari, ${ }^{1}$ Edy Machmud, ${ }^{1}$ Hasminar, ${ }^{2 *}$ Armawati Arafi, ${ }^{1}$ \\ Catarina A. Kristianti, ${ }^{3}$ Sitti Arpa, ${ }^{1}$ Maqfirah Amiruddin ${ }^{1}$
}

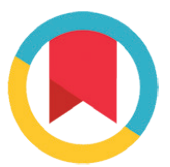

CrossMark

\title{
Abstract
}

Objective: To determine the effect of manufacturing technique of temporary imitative crown on the gingiva health.

Material and Methods: The clinical experimental study was conducted on 10 samples for each the manufacturing technique of temporary imitative crowns. On sample we conduct clinical examination by using plaque and gingival indexes, as well as DHE and scaling at the beginning of the study. And then we count the number of bacterial colonies by using swab method on the cervical part of the provisory. Data were analyzed by chi-square test.
Results: There was an effect between the manufacturing technique of temporary imitative crown with plaque and gingival indexes and there was a significant correlation between the manufacturing techniques of provisory on the gingiva health $(p<0.05)$.

Conclusion: There was an effect between the manufacturing techniques of the temporary imitative crown on the gingival health. The manufacturing technique of indirect-direct has minimum effect on the gingival health.
'Department of Prosthodontic, Faculty of Dentistry, Hasanuddin University, Makassar, Indonesia ${ }^{2}$ Dental Polyclinic, Puskesmas Tempe, Sengkang, Wajo, Indonesia ${ }^{3}$ Dental Polyclinic, General Hospital Manembo-nembo, Bitung, Indonesia

*Correspondence to: Hasminar, Dental Polyclinic, Puskesmas Tempe, Sengkang, Wajo, Indonesia

hasminarpangeran@gmail.com

Resieved: 12 February 2019

Revised: 13 April 2019

Accepted: 12 August 2019

Available Online 1 December 2019

Keywords: Provisory, Direct technique, Indirect, Indirect-direct, Gingival health

Cite this Article: Jubhari EH, Machmud E, Hasminar, Arafi A, Kristianti CA, Arpa S, Amiruddin M. 2019. The effect of fabrication techniques of temporary crowns on the gingiva health. Journal of Dentomaxillofacial Science 4(3): 133-136. D0I: 10.15562/jdmfs.v4i3.853

\section{Introduction}

A person who losses teeth either partial or complete, but not immediately replaced can cause the mastication process to be less maximal, disruption in speech, and appearance. Therefore, missing teeth should be replaced immediately to maintain oral health optimally. ${ }^{1}$

The primary goal of dental care, both fixed and removable dentures are to maintain the health of teeth that remains with the whole mastication system in order to function properly. To achieve this treatment objective, consideration should be given to several supporting factors, including periodontal factors of support teeth. ${ }^{1}$

Recently, the use of fixed dentures in the community is already very popular to replace the missing natural teeth. The manufacturing of fixed denture requires the natural teeth to be prepared on the cervical edge is a part of the preparation stage that determines the crown success rate. ${ }^{2}$

Provisory are manufactured to protect teeth from fractures, protecting the pulp from thermal sensitivity and bacterial invasion. ${ }^{3}$ It is an artificial crown that attached to the prepared tooth before the permanent crown is manufactured, ${ }^{3}$ before the permanent crown is attached the provisory is very important to be used because it determine the success of the treatment. It should protect the gingival margins and prevent edge leakage by forming intimate with the prepared teeth. The materials that can be used for the manufacture of provisory can be classified as acrylic, composite and metal. ${ }^{4}$

This provisory serves to protect dentin, maintain the appearance of teeth, and prevent teeth that have been prepared experience over-eruption by maintaining the point of contact and occlusion. In addition, during its use, the provisory is also used as a period in a care plan and communication with a laboratory to determine the clinical success of a permanent crown. It may only be required for 2-6 weeks or in some situations, but the provisory must remain in a satisfactory condition in the oral cavity for 12-18 months. ${ }^{3}$

In addition, the provisory plays an important role for the guidance of the fixed crowns and is a testing period for evaluating function, aesthetics and phonetics so that the crown can still meet expectations. $^{4,5}$

Various techniques are used for manufacturing provisory such as direct, indirect and combinations. Each technique has different benefits and number of visits. Provisory with direct technique is manufactured on a prepared tooth using a matrix in the mouth. ${ }^{6}$ There are several material to manufacture the provisory with direct technique includes polyvinyl siloxane, self-curing acrylic, composite, or new materials such as BIS-GMA composites. ${ }^{7}$

The provisory with indirect technique is manufactured on the working model by using 
the prepared matrix. This technique provides an opportunity for the patient to rest and allows the dentist to make a provisory. ${ }^{8}$

Meanwhile, in combination techniques, the provisory is manufactured before the tooth is prepared so that the time at the clinic can be reduced. This technique involves the laboratory to make a provisory based on a diagnostic model. The next step the tooth is prepared then the provisory is adjusted directly to the lining stage in the mouth. ${ }^{7}$

Fabricated provisory are available in various shapes and sizes. However, this provisory requires some modification, for example relief on internal part, re-contouring, lining and occlusal adjustment due to improper morphology and contours. ${ }^{9}$

In general, the provisory is manufactured in direct because the manufacturing of provisory in this technique is more efficient while the indirect is longer than direct technique because it takes time for making working model. Combination techniques require a longer time due to the manufacturing of provisory in the laboratory. ${ }^{8}$

Margin accuracy of the provisory is a requirement for the maintenance of gingival tissue health and periodontal. This margin accuracy is assessed by the difference between provisory margin and preparation end line. The shrinkage of polymerization occurring at the time of manufacturing a provisory may cause a margin difference. Margin accuracy of the provisory is very important to protect teeth from physical, chemical, bacterial, and heat exposure and to maintain gingival tissue health. ${ }^{10}$

The accuracy fit of provisory margin varies depending on manufacturing techniques and materials used. Provisory margins that manufactured with indirect techniques are considered to be more accurate than direct technique. ${ }^{11}$ Whereas the provisory is manufactured by using indirect-direct technique shows better margin accuracy compared with direct and indirect technique. ${ }^{12}$

Poor margin accuracy is characterized by gaps in the margin area causing plaque accumulation. This plaque leads to gingival inflammatory reactions and disrupt soft tissue. ${ }^{7}$ Several studies suggest that

Table 1 Distribution of sample and percentage of variable of the manufacturing technique of provisory, plaque index, gingival index

\begin{tabular}{lcc}
\hline Manufacturing Technique & Plaque Index & Gingiva index \\
\hline Direct & $24(60 \%)$ & $15(37.5 \%)$ \\
Indirect & $16(40 \%)$ & $20(50 \%)$ \\
Indirect-Direct & $0(0 \%)$ & $5(12.5 \%)$ \\
Fabricated & $0(0 \%)$ & $0(0 \%)$ \\
Total & $40(100 \%)$ & $40(100 \%)$ \\
\hline
\end{tabular}

the use of acrylic restorative materials may lead to an inflammatory reaction on the gingival tissue. ${ }^{13}$

The importance of the procedure of manufacturing a provisory, hence a research on the effect of the manufacturing technique of provisory on the gingival tissue health conducted.

\section{Material and Methods}

This is a planned experimental study by attach a temporary imitative crown and performed on patients who had damage to the anterior teeth. It was conducted in July - November 2016 on one of the private dentist practices in Makassar.

The population was patients treated by using the temporary imitative crowns on maxillary anterior teeth as much as 40 , each 10 samples of each manufacturing technique of temporary imitative crown (direct, indirect, indirect-direct, and fabricated).

To patients, we conduct clinical examination and count plaque and gingival indexes. The selected sample is given information and explanation of what to do and the side effects that can occur during the study. After that, we conduct clinical examination, presenting dental health education, scaling to control sample' oral hygiene at the beginning of study, patient is instructed to brush twice a day, morning after eat and night before sleep. Furthermore conduct preliminary molding, tooth preparation that will be manufactured a crown. Then, manufacture the provisory by using direct, indirect, indirect-direct and fabricated techniques and inserted by using fletcher cement, and assessment for retention and stability of provisory. Clinical examination is to determine plaque and gingival indexes, sampling the number of bacterial colonies using swab method on the cervical part of provisory.

Based on the formula of sample, the number of samples in this study was determined by 40 samples, each 10 samples for direct, indirect, indirect-direct and fabricated techniques.

\section{Results}

Characteristics of samples in this study will be presented in the table 1 and table 2.

\section{Discussion}

Provisory manufacturing to protect prepared teeth, it is an important stage in the manufacture of fixed denture. Provisory can be made using direct, indirect, and indirect-direct and fabricated techniques. Each techniques have advantage and disadvantageous. Direct technique is a technique that takes less time than other manufacturing techniques. ${ }^{14}$ 
Table 2 The relationship of manufacturing technique of provisory on plaque and gingival indexes manufacturing technique of provisory

\begin{tabular}{lccccc}
\hline Variabel & Direct & Indirect & Ind-direct & Fabricated & p \\
\hline Plaque Index & & & & & \\
$\quad$ Good & $5(50 \%)$ & $7(70 \%)$ & $8(80 \%)$ & $4(40 \%)$ & \\
$\quad$ Medium & $5(50 \%)$ & $3(30 \%)$ & $2(20 \%)$ & $6(60 \%)$ & 0.024 \\
$\quad$ Poor & $0(0 \%)$ & $0(0 \%)$ & $0(0 \%)$ & $0(0 \%)$ & \\
Total & $10(100 \%)$ & $10(100 \%)$ & $10(100 \%)$ & $10(100 \%)$ & \\
Gingiva Index & & & & & \\
$\quad$ Healthy & $4(40 \%)$ & $6(20 \%)$ & $8(80 \%)$ & $1(10 \%)$ & \\
$\quad$ Light Inflammation & $5(50 \%)$ & $2(60 \%)$ & $2(20 \%)$ & $7(70 \%)$ & 0.049 \\
$\quad$ Medium Inflammation & $1(10 \%)$ & $2(20 \%)$ & $0(0 \%)$ & $2(20 \%)$ & \\
Total & $10(100 \%)$ & $10(100 \%)$ & $10(100 \%)$ & $10(100 \%)$ & \\
\hline
\end{tabular}

Chi-square test: $\mathrm{p}<0.05$; significant

This technique is very fit for patients who very busy, so do not have much time to visit the clinic/ hospital. While the indirect-direct technique needs several time to visit to attach the provisory.

In this study, appear average distribution of plaque and gingival indexes on indirect-direct technique is smaller than indirect, direct and fabricated technique. This is due to poor margin accuracy on direct technique or the presence of a gap in the margin area. This gap occurs due to distortion at the time the crown is temporarily removed from the mouth and shrinkage polymerization caused by an exothermic reaction during polymerization. ${ }^{14}$ This gap causes the accumulation of plaque that is close to the gingival margin. As the results of the study, the accumulation of plaque more attaches to direct technique than indirect-direct technique. This plaque causes a gingival inflammatory reaction and will cause soft tissue disruption associated with periodontal disease. The accuracy of the end line is crucial in order to have esthetic and restoration values successfully. ${ }^{15}$

It is in accordance with the results of Ramkumar et al. ${ }^{10}$ study which states that provisory with indirect-direct technique shows better margin accuracy compared with direct and indirect techniques; this case because the manufacturing of provisory as conducted at dental laboratory then matched to the prepared tooth.

The accuracy of margin is the basis for the maintenance of periodontal tissue and the success of the provisory; a good margin shows no difference between the provisory margin and the end line of the preparation tooth. ${ }^{14}$

The most important consideration during the manufacture of a provisory by direct technique is heat produced from the exothermic reaction during polymerization. This technique of polymerization reaction takes place in the prepared tooth and the matrix used. While the indirect technique, polymerization reaction occurs on the prepared tooth model and the matrix so that the heat produced is outside the mouth. The indirect-direct combination technique uses only a thin layer of acrylic used for reline of provisory that has been manufactured in the laboratory. ${ }^{14}$ As well as the fabricated and direct techniques because the process of manufacturing takes less time but it is difficult to get the precision of restoration on the preparation tooth. This instability might create a gap in the cervical area that is susceptible to plaque attachment.

Flores et al. ${ }^{16}$ in her study about the effect of crown margins on periodontal health and the number of bacteria in humans found an increase in scores on plaque and gingival indexes. The result of research shows a relationship between the manufacturing techniques of provisory with the number of bacterial colonies.

Several studies have reported that the crown margins stimulate the bacteria re-colonization that can attack the tooth surface. The bacterial community of dental plaque occurs due to physiological changes and composition as a result of the environmental stresses produced by the placement of dental restorations. ${ }^{17}$

The result of research was also found in Rawashdeh et al. ${ }^{18}$ study which states that crown restoration materials have a significant effect on the bacterial counts. ${ }^{18}$

Periodontal disease should be recognized and treated prior to the manufactures of denture, especially fixed denture, which is fully supported by the dental support tissue, while the position of the gum can be used as a guideline for edge position of perfect fixed denture associated with the aesthetic factor. $^{19,20}$

The optimal health of the gingival tissue must be obtained prior to a fixed denture placement 
procedure and caring during the stage. While, healthy gingival tissue during the preparation procedure and slightly trauma will not have an effect on the gingival tissue. ${ }^{15}$

\section{Acknowledgment}

None

\section{Conflict of Interest}

The authors Report no conflict of interest.

\section{References}

1. Lesmana RA. Faktor-faktor periodontal yang harus dipertimbangkan pada perawatan gigi tiruan cekat. Jurnal kedokteran Gigi Universitas Indoneisia 1999;6: 35-36.

2. Prajitno HR. Ilmu gigi tiruan jembatan. Jakarta: EGC; 1991. p. 95-99.

3. Wassel RW, George GS, Ingladew RP, et al. Crowns and other extra-coronal restorations: provisional restorations. Br Dent J 2002;192: 619-630.

4. Bennani V. fabrication of an indirect-direct provisional fixed partial denture. J Posthet Dent 2000;84: 364-365.

5. Farah JW, Power JM. Temporary cements. The Dental Advisor 2005;22: 2-4.

6. TM Le. An. Analysis of direct versus indirect provisionalization. Dent Today 2006;25: 136-147.

7. Santos GC, Santos MJ. Selecting a temporary cement; a case report. Dent restorations. Dentalaegis 2012;8: 1-9.

8. Regish KM, Sharma D, Prithviraj DR. Techniques of fabrications of provisional restoration, An overview. Int J Dent 2011;7: 1-5.

9. Prema, Shetty SR, Raj DRP. Marginal fit of provisional crowns fabricated by direct, indirect and combination techniques: A scanning microscopic study. Arc Oral Sci Res 2012;2: 23-29.
10. Ramkumar V, Sangeetha A, Kumar V. Effect of water temperature on the fit of provisional crown margins during polymerization: An in vitro study. J Pharm Bioallied Sci 2012;4: 376-383.

11. Howard ES, Roseanne JM. Techniques to facilitate placement of provisional restorations. Dentalaegis 2012;8: $1-9$.

12. Holand W, Schweiger M, Rheinberger VM, Kappert H. Review bioceramics 2009;108: 373-380.

13. ADA PPR. Temporary cements. 2011;6: 13-16.

14. Yanikoglu ND, Bayindir F, Kurklu D, et al. Flexural strength oftemporary Restorative Materials Storedin different solutions. J Stomatol 2014;4: 291-298.

15. Singh K, Gupta N, Chowdhary N, Kapoor V, Effects of tooth and poorly designed artifical crowns on health of periodontium and esthetics: a case report. J Pharm Biomed Sci 2012;24: 12-15.

16. Flores DJ, Zafiropoulas GG, Cianco S. The effect of crowns margin location on palque and periodontal health. Int J Periodontics Restorative Dent 1989;9: 197-205.

17. Sood S, Gupta S. periodontal-restorative ineractions: a riview. Indian J Cli Prac 2013;23: 707-714.

18. Rawashdeh RY, Malkawi HI, Al-Hiyasat AS. The effect of crown restorations on the types and counts of cariogenic bacteria. Jordan J Bio Sci 2008;1: 100-104.

19. Shah SA, Naqash TA. Comparative evaluation of vertical marginal accuracy of chemically polymerized polymenthyl methacrylate provisional resorative crown using direct, indirect and combination thecniques: a research. Int J Health Sci Res 2015;5: 136-138.

20. Thahir H, Djais AI, Wendy S, Achmad MH, Akbar FH. Management of maxillary labial frenum with comparison of conventional and incision below the clamp techniques: a case report. J Dentomaxillofac Sci 2018;3: 61-66.

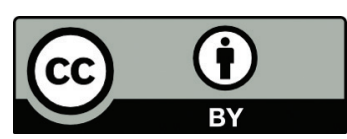

This work is licensed under a Creative Commons Attribution 